\title{
Ketogenesis from Lactate in Rat Liver during the Perinatal Period
}

\author{
ANGELES ALMEIDA, JUAN P. BOLAÑOS, AND JOSÉ M. MEDINA \\ Departamento de Bioquímica y Biologia Molecular, Facultad de Farmacia, Universidad de Salamanca, E37080, \\ Salamanca, Spain
}

\begin{abstract}
Lactate, which accumulates in neonatal plasma during the first hours after delivery, is used by neonatal tissues as a source of energy and carbon skeleton. In this work, lactate use by rat liver during late gestation (last $3 \mathrm{~d}$ ) and early neonatal life ( $6 \mathrm{~h}$ postpartum) has been studied. The rate of lactate use by liver was compared with that found with oleate, inasmuch as fatty acids are the main substrates for the liver after the onset of lactation. The main fate of lactate in the liver during the perinatal period was ketone bodies, preferentially over $\mathrm{CO}_{2}$ and lipids. The rate of oxidation of lactate and its incorporation into lipids decreased during late gestation, but the rate of ketogenesis from lactate remained high during this period. After birth, the rate of lactate oxidation sharply increased, but lipogenesis decreased and ketogenesis was maintained. The rates of oleate oxidation and ketogenesis from oleate were two orders of magnitude lower than those from lactate. However, the rate of oleate incorporation into lipids was only 4-fold lower than that observed from lactate under the same circumstances. Our results suggest that lactate is a major substrate for the liver during the perinatal period because it is mainly incorporated into ketone bodies. This may target lactate carbons to different neonatal tissues. (Pediatr Res 31: 415-418, 1992)
\end{abstract}

\section{Abbreviations}

PSWL, partially sliced whole liver

During the late stages of gestation, the rat fetus accumulates a substantial amount of lactate (1), probably as a consequence of the activity of anaerobic glycolysis in the placenta $(2,3)$ and, possibly, in some maternal (4) and fetal tissues (5). During the immediate postnatal period, blood lactate concentrations increase further, but lactate is rapidly removed during the first $2 \mathrm{~h}$ of extrauterine life in the rat $(1,6)$ and human baby $(7)$. Lactate is therefore available as a putative metabolic fuel throughout the perinatal period. It has been reported that lactate is used during the perinatal period by rat lung $(8)$ and brain $(2,9,10)$ and by dog (11) and human (12) brain. This suggests that lactate may play an important role in fuel supply to fetal and neonatal tissues during the perinatal period (13).

Because the overall rate of lactate use after delivery is very high (14) and cannot only be accounted for by the rates of use in brain (10) and lung (8), we were prompted to investigate the

Received August 1, 1991; accepted December 4, 1991.

Correspondence and reprint requests: Prof. José M. Medina, Departamento de Bioquimica y Biologia Molecular, Facultad de Farmacia, Universidad de Salamanca, Aptdo. 449, E37080 Salamanca, Spain.

Supported in part by a grant from CICYT, Spain. A.A. is a recipient of a fellowship from the Ministerio de Educacion y Ciencia, Spain. J.P.B. is a recipient of a fellowship from the F.I.S.S.S., Ministerio de Sanidad y Consumo, Spain. possible role of the liver in lactate metabolism during the perinatal period. We have previously reported (15) that early neonatal liver uses lactate as a source of energy and carbon skeleton preferentially over glucose or oleate. The present work investigated the time-course of lactate use by the liver during the perinatal period.

\section{MATERIALS AND METHODS}

Reagents. Enzymes were obtained from Boëhringer (Mannheim, Germany). Coenzymes, oleic acid, and essentially fatty acid-free albumin were purchased from Sigma Chemical Co. (St. Louis, MO). L-Lactic acid was obtained from Serva Feinbiochemica (Heidelberg, Germany). Radioactive substrates were obtained from New England Nuclear (Boston, MA).

Animals. Albino Wistar rats housed at $22 \pm 2^{\circ} \mathrm{C}$ with a $12-\mathrm{h}$ light-dark cycle and fed on stock laboratory diet (carbohydrate $58.7 \%$, protein $17.0 \%$, fat $3.0 \%$, and added salts and vitamins) were used for the experiments. Virgin females weighing 200-250 $\mathrm{g}$ were caged overnight with males. Conception was considered to occur at $0100 \mathrm{~h}$ and was confirmed the next morning by the presence of spermatozoa in vaginal smears. Fetuses weighing $2.31 \pm 0.01,3.62 \pm 0.01$, or $5.35 \pm 0.03 \mathrm{~g}$ (mean \pm SEM) were delivered on d 19.5, 20.5, or 21.5 of gestation ( $21.7 \mathrm{~d}$ for full gestation), respectively, by rapid hysterectomy after cervical dislocation of the mother. Newborns were carefully wiped, and the umbilical cords were tied and cut. All of these processes were carried out in a cabin at $37^{\circ} \mathrm{C}$. Newborns were kept in an incubator at $37^{\circ} \mathrm{C}$ in a continuous stream of water-saturated air without feeding for $6 \mathrm{~h}$. The newborns were killed by decapitation, and their livers were immediately used for the experiments.

Liver preparation. Liver preparation, essentially based on the method described by Pollard and Dutton (16), was carried out as follows: whole livers were washed in physiologic saline $(0.9 \%$ $\mathrm{NaCl}$; wt/vol), partially sliced by two longitudinal incisions (PSWL), and incubated in $3 \mathrm{~mL}$ of phosphate physiologic saline (17) containing $2.5 \%(\mathrm{wt} / \mathrm{vol})$ of essentially fatty acid-free albumin, $0.25 \mu \mathrm{Ci}$ of $\mathrm{L}-\left[\mathrm{U}_{-}{ }^{14} \mathrm{C}\right]$ lactate or $0.5 \mu \mathrm{Ci}$ of $\left[1-{ }^{14} \mathrm{C}\right]$ oleate and the desired concentrations of the unlabeled substrates. The gas phase was pure $\mathrm{O}_{2}$. Incubations were carried out at $37^{\circ} \mathrm{C}$ and stopped after $1 \mathrm{~h}$ with $0.4 \mathrm{~mL}$ of $20 \%(\mathrm{vol} / \mathrm{vol}) \mathrm{HClO}_{4}$, although shaking was continued for a further $20 \mathrm{~min}$.

Analytical procedures. The radioactive $\mathrm{CO}_{2}$ trapped by $20 \%$ (wt/vol) $\mathrm{KOH}$ was measured by liquid-scintillation counting. Blanks without PSWL were carried out in parallel to measure background radioactivity that was subtracted from the sample values. After incubation, the PSWL was frozen and powdered under liquid nitrogen. Lipids were extracted with $6 \mathrm{~mL}$ of chloroform:methanol $(2: 1, \mathrm{vol} / \mathrm{vol})$, and the extract was washed once with $3 \mathrm{~mL}$ of $0.3 \% \mathrm{NaCl}$ saturated with chloroform (18). A $3.5-\mathrm{mL}$ sample of the organic phase was dried under $\mathrm{N}_{2}$ and used for liquid-scintillation counting. The specific radioactivity of the substrates found in the blanks was used for the calculations.

The incubation medium was used to determine the radioactiv- 
ity incorporated into acetoacetate by precipitating the acetoacetate as the Deniges salt (Hg-acetone complex) as in the method described by Bates et al. (19). Thus, $30 \mu \mathrm{mol}$ of carrier acetoacetate, $0.22 \mathrm{~mL}$ of $9 \mathrm{M} \mathrm{H}_{2} \mathrm{SO}_{4}$, and $0.78 \mathrm{~mL}$ of $10 \%$ (wt/vol) $\mathrm{HgSO}_{4}$ in $2 \mathrm{M} \mathrm{H}_{2} \mathrm{SO}_{4}$ were added to $0.5 \mathrm{~mL}$ of the neutralized perchloric extract of the medium. The samples were stoppered, mixed, and placed in a boiling water bath for $30 \mathrm{~min}$. The $\mathrm{Hg}$ acetone precipitate was cooled, centrifuged, and washed twice with ice-cold distilled water. The precipitate was then dissolved in $2 \mathrm{M} \mathrm{HCl}$ and used for the measurement of radioactivity. The radioactivity incorporated into total ketone bodies was calculated from the 3-hydroxybutyrate/acetoacetate ratio measured in the incubation medium. The neutralized perchloric extract of the medium from blanks incubated without PSWL was used to measure the Hg-acetone complex obtained with lactate, which was negligible. L-Lactate was measured as described by Gutmann and Wahlefeld (20), and 3-hydroxybutyrate and acetoacetate were measured as described by Williamson et al. (21).

Calculations. Radioactivity (dpm) found in $\mathrm{CO}_{2}$, lipids, or ketone bodies was divided by the specific radioactivity of substrate (lactate or oleate) in the blanks. The results were expressed as $\mu \mathrm{mol}$ of substrate (lactate or oleate) incorporated into $\mathrm{CO}_{2}$, lipids, or ketone bodies/h/g wet wt.

Validation of preparation. The rates of lactate oxidation and lipogenesis by PSWL were linear with liver weight $(r=0.62, p<$ 0.001 and $r=0.79, p<0.001$, respectively) and incubation time ( $r=0.99, p<0.001$ and $r=0.99, p<0.001$, respectively) up to $2 \mathrm{~h}$ (results not shown). PSWL from rat fetus or newborns proved to be a suitable preparation in which to study ureagenesis (22) and lactate metabolism (15). After $1 \mathrm{~h}$ of incubation, the ATP/ ADP ratio remained high (22), showing that oxygen supply was enough to maintain active metabolic processes.

\section{RESULTS}

Lactate use by rat liver during perinatal period. Oxidation of lactate to $\mathrm{CO}_{2}$ linearly decreased during late gestation, reaching a minimum before birth (Fig. 1a). However, after delivery the rate of lactate oxidation increased 2 -fold, becoming similar to that found at $20.5 \mathrm{~d}$ of gestation (Fig. 1a). Similarly, the rate of lipogenesis from lactate (Fig. $1 b$ ) decreased linearly during the last $3 \mathrm{~d}$ of gestation and remained low at $6 \mathrm{~h}$ after birth. Ketogenesis from lactate persisted throughout the perinatal period (Fig. 1C) and was higher than the rates of oxidation and lipogenesis from lactate observed in rat liver in the same circumstances (Fig. $1 a$ and $b$ ).

Oleate use by rat liver during perinatal period. The oxidation of oleate to $\mathrm{CO}_{2}$ was very low during late gestation but increased 7 -fold at $6 \mathrm{~h}$ after delivery (Fig. $2 a$ ). The rate of oleate esterification (Fig. $2 b$ ) decreased during the last $3 \mathrm{~d}$ of gestation but was markedly enhanced after delivery. Ketogenesis from oleate followed a pattern similar to that found for oleate oxidation (Fig. $2 c)$.

\section{DISCUSSION}

As previously reported, lactate is an important substrate for perinatal brain (for a review, see Ref. 13) and lung (8). The results of the study presented here show that lactate is also an important substrate for neonatal liver; it is used as an energy source and also as a precursor of lipids and ketone bodies. The rate of lactate use by the liver has been compared to that of oleate, inasmuch as fatty acids are the main substrates for the liver after the onset of lactation (23).

Ketogenesis from oleate was very low during late gestation but rose sharply immediately after delivery (Fig. $2 c$ ). Because ketogenesis from lactate was high under the same circumstances (Fig. $1 c$ ), oleate incorporation into ketone bodies is not likely to be limited by the activity of the 3-hydroxy-3-methylglutaryl-CoA pathway (24). In addition, the oxidation of oleate was very low

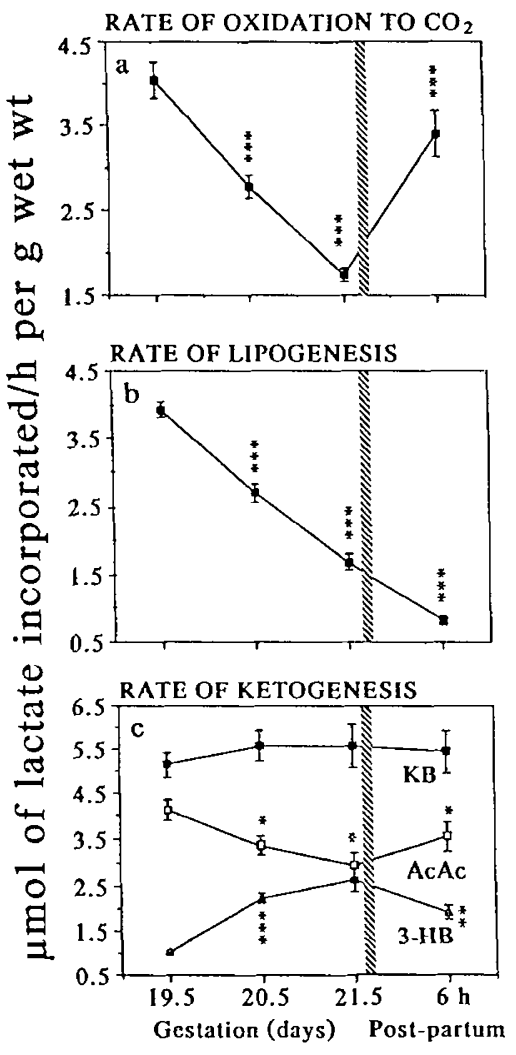

Fig. 1. The fate of lactate in perinatal rat liver in vitro. PSWL were incubated with $0.25 \mu \mathrm{Ci}$ of $\mathrm{L}-\left[\mathrm{U}-{ }^{14} \mathrm{C}\right]$ lactate and $10.2 \pm 0.4 \mathrm{mM}$ lactate. The incorporation into $\mathrm{CO}_{2}(a)$, lipids $(b)$, and ketone bodies $(c)$ was measured as described in Materials and Methods. Results are expressed in $\mu \mathrm{mol}$ of lactate incorporated $/ \mathrm{h} / \mathrm{g}$ of liver wet $\mathrm{wt}$ and are means \pm SEM from seven to 26 fetuses weighing $2.31 \pm 0.02$ (19.5 d), $3.62 \pm 0.01$ $(20.5 \mathrm{~d})$, and $5.35 \pm 0.03 \mathrm{~g}(21.5 \mathrm{~d})$ and seven to nine newborns weighing

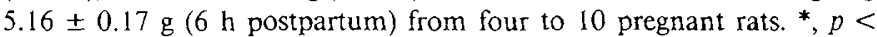
$0.05 ;{ }^{* *}, p<0.01$, and ${ }^{* * *}, p<0.001$ vs previous value. $K B$, total ketone bodies; $A C A C$, acetoacetate; and 3-HB, 3-hydroxybutyrate.

during late gestation but increased sharply immediately after delivery (Fig. 2a). This is consistent with the time course of the activities of the liver enzymes involved in fatty acid oxidation, which are very low during late gestation but increase markedly after birth (25). Actually, our results (Fig. 2) suggest that during the perinatal period oleate use by the liver is limited by a common step for oxidation, esterification, and ketogenesis. Whether this putative step that limits oleate use is acyl-CoA synthetase (EC 6.2.1.3) activity, which is very low during the fetal period but increases sharply after delivery (25), remains to be elucidated.

The rate of lipogenesis from lactate decreased linearly during late gestation, and this tendency persisted during the early neonatal period (Fig. $1 b$ ). This is consistent with the decrease in the rate of total lipogenesis measured in vivo under the same circumstances (26). Because insulin concentrations do not decrease during this period (27), it has been suggested that the decrease in lipogenic capacity occurring during late gestation must be due to the concurrent decrease in plasma progesterone concentrations (28). After delivery, however, the decreased insulin/glucagon ratio $(29,30)$ may be responsible for the further decrease in the rate of lipogenesis (Fig. 1b). Lactate oxidation decreased linearly during late gestation, reaching a minimum before birth (Fig. 1a). However, immediately after delivery the rate of lactate oxidation increased to values similar to those observed on d 20.5 of gestation. This was coincident with the increase in the total pyruvate dehydrogenase complex (EC 1.2.4.1) activity that occurred after delivery (31). Despite the foregoing, these results may be explained by assuming that the rate of lactate oxidation would follow the changes in the mitochondrial respiratory activ- 

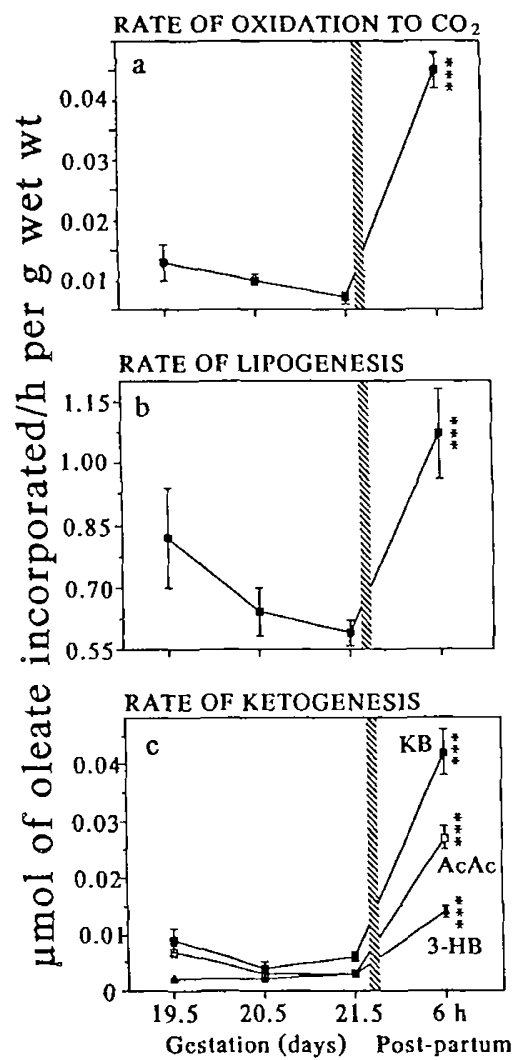

Fig. 2. The fate of oleate in perinatal rat liver in vitro. PSWL were incubated with $0.05 \mu \mathrm{Ci}$ of $\left[1-{ }^{14} \mathrm{C}\right]$ oleate and $1 \mathrm{mM}$ oleate. The incorporation into $\mathrm{CO}_{2}(a)$, lipids $(b)$, and ketone bodies $(c)$ was measured as described in Materials and Methods. Results are expressed in $\mu \mathrm{mol}$ of oleate incorporated $/ \mathrm{h} / \mathrm{g}$ of liver wet wt and are means \pm SEM from seven to 12 fetuses weighing $2.23 \pm 0.04(19.5 \mathrm{~d}), 3.43 \pm 0.09$ ( $20.5 \mathrm{~d})$, and $5.34 \pm 0.05 \mathrm{~g}(21.5 \mathrm{~d})$ and seven to nine newborns weighing $5.26 \pm 0.07$ $\mathrm{g}\left(6 \mathrm{~h}\right.$ postpartum) from four to 10 pregnant rats. ${ }^{* *}, p<0.001$ vs previous value. $K B$, total ketone bodies; $A C A C$, acetoacetate; and $3-H B$, 3-hydroxybutyrate

ity occurring during the perinatal period. Thus, the respiratory control ratio of liver mitochondria was very low during late gestation and increased sharply during the $1 \mathrm{st} h$ of extrauterine life (32). Consequently, this increase in the respiratory efficiency of mitochondria may result in an increase in tricarboxylic acid cycle activity and therefore in the rate of lactate oxidation. It should be mentioned that immediately after birth oleate oxidation followed a pattern similar (Fig. $2 a$ ) to that found for lactate oxidation (Fig. 1a), suggesting that independently of acyl-CoA synthetase activity, oleate oxidation may also be limited by the efficiency of the respiratory machinery. Ketogenesis from lactate was high during late gestation and the first hours of extrauterine life as compared with the rates of oxidation and lipogenesis from lactate observed under the same circumstances (Fig. 1). It should also be noted that the rates of lactate use (Fig. 1) were much higher than those observed for oleate (Fig. 2), suggesting that during the perinatal period lactate is preferentially used over oleate. Inasmuch as the rate of glucose utilization has also been found to be very low under these circumstances (15), it may be suggested that lactate is the main metabolic substrate for the liver during the perinatal period.

There is considerable evidence to suggest that lactate plays a relevant role in the homeostasis mechanisms of fuel supply to tissues during the perinatal period. Thus, it has been reported that lactate is used by rat lung (8), heart (Fernández E, Medina $\mathrm{JM}$, personal communication), and brain (2, 9, 10, 33). The present results suggest that rat liver also uses lactate during the perinatal period. Actually, lactate is used by the perinatal rat liver not only as a source of energy and carbon skeleton but also as a precursor of ketone bodies (Fig. 1c). This may be of physiologic significance because lactate is massively synthesized during the perinatal period. Thus, during late gestation, lactate is synthesized by the placenta $(2,3)$ and possibly by maternal $(4)$ and fetal tissues (5). Moreover during the early postnatal period lactate is actively synthesized, probably as a consequence of the anaerobic glycolysis brought about by postnatal hypoxia (34). As a result, lactate is accumulated in maternal (4), fetal, and early neonatal blood (1) and is available to the tissues during the perinatal period. Our results thus suggest that lactate is actively used by perinatal rat liver (Fig. 1) in preference to other putative substrates for the liver under these circumstances, such as oleate (Fig. 2) or glucose (15). This corroborates the role played by lactate as the major metabolic fuel during late gestation and the early neonatal period (13). Moreover, ketone bodies from lactate may be used by fetal brain, liver, kidney, and carcass $(35,36)$ and neonatal brain (37) as a system to provide carbon from lactate to these tissues. It should be mentioned that decreased rates of ketogenesis observed in low birth-weight infants (38) may be due to the low rates of ketogenesis from fatty acids presumably occurring in human fetus during late gestation. If so, the importance of lactate as an alternative substrate to fatty acids for ketogenesis should be stressed.

The fact that lactate is mainly converted to ketone bodies, despite its being used directly by fetal and neonatal tissues without transformation $(2,8-10,33)$, is intriguing. However, the conversion of lactate into ketone bodies is not an energy-consuming pathway and ketone bodies may be more ready-to-use substrates. Similarly, the transformation of lactate into ketone bodies may channel carbon from lactate to tissues whose enzymatic machinery for lactate use is defective or still immature.

In conclusion, our results show that lactate is actively used by fetal and early neonatal rat liver, suggesting that this substrate is a pluritissular fuel during the perinatal period. In the liver, lactate is mainly transformed into ketone bodies, possibly constituting a system for targeting carbon to different tissues.

Acknowledgment. The authors thank J. Villoria for his technical assistance.

\section{REFERENCES}

1. Juanes MC, Arizmendi C, Medina JM 1986 Attenuation of postnatal hypoxia in the premature newborn rat by maternal treatment with dexamethasone: its relationship with lung phospholipid content. Biol Neonate 50:337-344

2. Shambaugh III GE, Koehler RA, Freinkel N 1977 Fetal fuels II: contributions of selected carbon fuels to oxidative metabolism in rat conceptus. Am J Physiol 233:E457-E461

3. Palacín M, Lasunción MA, Herrera E 1987 Lactate production and absence of gluconeogenesis from placental transferred substrates in fetuses from fed and 48-h starved rats. Pediatr Res 22:6-10

4. Valcarce C, Cuezva JM, Medina JM 1985 Increased gluconeogenesis in the rat at term gestation. Life Sci 37:553-560

5. Battaglia FC 1989 An update of fetal and placental Imetabolism:carbohydrate and amino acids. Biol Neonate 55:347-354

6. Cuezva JM, Moreno FJ, Medina JM, Mayor F 1980 Prematurity in the rat. I. Fuels and gluconeogenic enzymes. Biol Neonate 37:88-95

7. Persson B, Tunell R 1971 Influence of environmental temperature and acidosis on lipid mobilization in the human infant during the first two hours after birth. Acta Paediatr Scand 60:385-398

8. Patterson CE, Konini MV, Selig WM, Owens CM, Rohades R 1986 Integrated substrate utilization by perinatal lung. Exp Lung Res 10:71-86

9. Arizmendi C, Medina JM 1983 Lactate as an oxidizable substrate for rat brain in vivo during perinatal period. Biochem $\mathrm{J} 214: 633-635$

10. Fernández E, Medina JM 1986 Lactate utilization by the neonatal rat brain in vitro. Competition with glucose and 3-hydroxybutyrate. Biochem J 234:489492

11. Hellmann J, Vanucci RC, Nardis E 1982 Blood-brain barrier permeability to lactic acid in the newborn dog: lactate as a cerebral metabolic fuel. Pediatr Res 16:40-44

12. Fernandes J, Berger R, Smit GPA 1984 Lactate as a cerebral metabolic fuel for glucose-6-phosphate deficient children. Pediatr Res 18:335-339

13. Medina JM, Fernández E, Bolaños JP, Vicario C, Arizmendi C 1990 Fuel supply to the brain during the early neonatal period. In: Cuezva JM, PascualLeone MA, Patel MS (eds) Endocrine and Biochemical Development of the Fetus and Neonate. Plenum Press, New York, pp 175-193

14. Medina JM, Cuezva JM, Mayor F 1980 Non-gluconeogenic fate of lactate during the early neonatal period in the rat. FEBS Lett 114:132-134 
15. Almeida A. Bolaños JP, Medina JM 1990 Lactate utilization by neonatal rat liver in vitro. Biochem Soc Trans 18:1274-1275

16. Pollard MR, Dutton GJ 1982 Liver snips. A simple, rapid and reproducible method for studying metabolism in small fragments of tissue, as applied to glucuronidation in rat liver. Biochem J 202:469-473

17. Elliott KAC 1969 The use of brain slices. In: Lajtha A (ed) Handbook of Neurochemistry. Plenum Press, New York, pp 103-114

18. Folch J, Lees M, Sloane-Stanley GH 1957 A simple method for the isolation and purification of total lipides from animal tissues. $J$ Biol Chem 226:497509

19. Bates MW, Krebs HA, Williamson DH 1968 Turnover rates of ketone bodies in normal, starved and alloxan-diabetic rats. Biochem $\mathrm{J}$ 1 10:655-661

20. Gutmann I, Wahlefeld AW $1974 \mathrm{~L}-(+)$-Lactate determination with lactate dehydrogenase and NAD. In: Bergmeyer HU (ed) Methods of Enzymatic Analysis, Verlag Chemie International, Deerfield Beach, FL, pp 1464-1468

21. Williamson DH, Mellanby J, Krebs HA 1962 Enzymic determination of $D(-)$ $\beta$-hydroxybutyric acid and acetoacetic acid in blood. Biochem J 82:90-96

22. Bolaños JP. Fernández E, Medina JM 1990 Effect of hypoxia on urea synthesis in neonatal rat liver in vitro. Biochem Soc Trans 18:1284-1285

23. Girard GS, Cuendet EB, Marliss A, Kevran M, Rieutort R, Assan R 1973 Fuels, hormones and liver metabolism at term during the early postnatal period in the rat. J Clin Invest 53:3190-3200

24. Lee LPK, Fritz IB 1971 Hepatic ketogenesis during development. Can J Biochem 49:599-605

25. Foster PC, Bailey E 1976 Changes in the activities of the enzymes of hepatic fatty acid oxidation during development of the rat. Biochem J 154:49-56

26. Lorenzo M, Caldés T, Benito M, Medina JM 1981 Lipogenesis in vivo in maternal and foetal tissues during late gestation in the rat. Biochem $J$ 198:425-428

27. Lorenzo M, Benito M. Caldés T, Medina JM 1983 Regulation of lipogenesis in vivo by glucose availability and insulin secretion in maternal and foetal tissues during late gestation in the rat. Effect of glucose intubation, streptozotocin-induced diabetes and starvation. Biochem J 216:695-699

28. Lorenzo M, Roncero C, Benito M 1986 The role of prolactin and progesterone in the regulation of lipogenesis in maternal and foetal rat liver in vivo and in isolated hepatocytes during the last day of gestation. Biochem J 239:135139

29. Di Marco PN, Ghisalberti AV, Martin CE, Oliver IT 1978 Perinatal changes in liver corticosterone, serum insulin and plasma glucagon and corticosterone in the rat. Eur $J$ Biochem 87:243-247

30. Martín A, Caldés T, Benito M, Medina JM 1981 Regulation of glycogenolysis in the liver of the newborn rat in vivo. Biochim Biophys Acta 672:262-267

31. Serrano E, Luis AM, Encabo P, Alconada A, Ho L, Patel MS, Cuezva JM 1989 Rapid postnatal induction of the pyruvate dehydrogenase complex in rat liver mitochondria. In: Roche TE, Patel MS (eds) Alpha-Keto Acid Dehydrogenase Complexes: Organization, Regulation, and Biomedical Ramifications. Ann NY Acad Sci, pp 412-415

32. Pollak JK 1975 The maturation of the inner membrane of foetal rat liver mitochondria. Biochem J 150:477-488

33. Itoh T, Quastel $J_{H} 1970$ Acetoacetate metabolism in infant and adult rat brain in vitro. Biochem J 116:641-655

34. Cuezva JM, Moreno FL, Medina JM 1981 Blood oxygen concentrations in premature newborn rats during the early neonatal period. IRCS Med Sci 9:644

35. Shambaugh III GE, Mrozak SC, Freinkel N 1977 Fetal fuels. I. Utilization of ketone by isolated tissues at various stages of maturation and maternal nutrition during late gestation. Metabolism 26:623-635

36. Dierks-Ventling C 1971 Prenatal induction of ketone body enzymes in the rat. Biol Neonate 19:426-433

37. Williamson DH, Buckley BM 1973 The role of ketone bodies in brain development. In: Hommes FA, Van der Berg CF (eds) Inborn Errors of Metabolism. Academic Press, New York, pp 81-96

38. Sann L, Divry P Cartier B, Vianey-Laud C, Maire I 1987 Ketogenesis in hypoglycemic neonates. Carnitine and dicarboxylic acids in neonatal hypoglycemia. Biol Neonate 52:80-85 